\title{
Study of the effect of stepped dosing of sulfuric acid in the process of decomposition of apatitis
}

\author{
(C) Rauf F. Sabirov, ${ }^{+}$Alexey F. Makhotkin, Yury N. Sakharov, \\ Igor A. Makhotkin, Ilya Yu. Sakharov, and Roman V. Durnik
}

Department of Chemical Plant Equipment. Kazan National Research Technological University.

Karl Marx St., 68. Kazan, 420015. Russia.Phone: +7927417 7218.E-mail: Sabirov.9090@mail.ru, ohz.kstu@rambler.ru,usacharas@mail.ru,oxzkstu@kstu.ru,wisefellow@mail.ru,durnikroman1@gmail.com

Keywords: phosphoric acid, apatite, sulfuric acid, technology.

*Supervising author; ${ }^{+}$Corresponding author

\begin{abstract}
An experimental study of the effect of stepwise dosing of sulfuric acid in the process of decomposition of apatite with sulfuric acid has been performed. The process of decomposition of apatite in the apatite$\mathrm{H}_{3} \mathrm{PO}_{4}-\mathrm{H}_{2} \mathrm{SO}_{4}-\mathrm{H}_{2} \mathrm{O}$ system was carried out with stepwise dosing of sulfuric acid. At the beginning of the process, the calculated amount of phosphoric acid and half of the stoichiometric amount of sulfuric acid required for the decomposition of the loaded amount of apatite was loaded into the batch reactor. It was experimentally shown that the $\mathrm{pH}$ of the reaction mixture at the beginning of the process increases to a $\mathrm{pH}$ value of 6.13, at the same time there is a decrease in the concentration of sulfuric acid and the formation of phosphoric acid, this is due to the decomposition of apatite in the reaction mixture. Already in the seventh minute, the concentration of sulfuric acid is zero, and the concentration of phosphoric acid has the first peak value, after which it begins to decrease. Thus, at the beginning of the process, the formation of phosphoric acid occurs due to the decomposition of apatite with sulfuric acid. Since sulfuric acid was added at the beginning of the process with a deficiency $(0.5 \mathrm{~mol})$ of sulfuric acid is not enough to decompose the charged apatite, a decrease in the concentration of phosphoric acid and the formation of monocalcium phosphate are observed after the peak. This is due to the consumption of phosphoric acid on the decomposition of the remaining apatite with the formation of monocalcium phosphate. At the 140th minute, the remaining stoichiometric amount of sulfuric acid was added to the reactor $(0.5 \mathrm{~mol})$, a sharp drop in $\mathrm{pH}$ to 5.48 and a simultaneous increase in the concentration of phosphoric acid were observed. Consequently, sulfuric acid is consumed for the decomposition of monocalcium phosphate. Thus, it was shown that with an insufficient amount of sulfuric acid, the resulting phosphoric acid is spent on the decomposition of apatite with the formation of monocalcium phosphate. Adding sulfuric acid makes it possible to extract production phosphoric acid from monocalcium phosphate.
\end{abstract}

\section{References}

[1] L.Ya. Tereshchenko, I.I. Orekhov, M.Ya. Laptev. Production of phosphoric and sulfuric acids. Printing house No.6B, Leningrad. 1968. P.5. (russian)

[2] B.A. Kopylev. Extraction phosphoric acid technology. Chemistry, Leningrad. 1981. P.99-101. (russian)

[3] A.V. Tretyakov, V.F. Markov, and S.B. Yaroshuk. Creation of lipid shells microcapsules of insecticides based on chlorpyrifos of trade mark GET. Butlerov Communications. 2018. Vol.55. No.9. P.37-42. DOI: 10.37952/ROI-jbc-01/18-55-9-37

[4] Kolesnikov A.V. Investigations of the influence of di-2-ethyl-hexyl phosphoric acid on the parameters of electrolysis of zinc from acidic solutions. Butlerov Communications. 2018. Vol.55. No.8. P.127-133. DOI: $10.37952 / R O I-j b c-01 / 18-55-8-127$

[5] G.A. Ovchinikov, V.A. Gorsky, D.A. Kirilov, V.S. Tukhvatshin, V.A. Kraykin, and G.R. Talipova. Kinetics adsorption of 4,4-dimethyl-1,3-dioxane from aqueous solutions by carbon porous materials in the presence of phosphoric acid. Butlerov Communications. 2016. Vol.48. No.10. P.83-86. DOI: 10.37952/ROI-jbc-01/16-48-10-83

[6] R.Sh. Gainutdinov, M.Yu. Lazarev. Differential and integral methods for the determination of kinetic parameters. Bulletin of Kazan Technological University. 2012. Vol.15. No.8. (russian)

[7] Chemical encyclopedia. Editorial: Knunyants I.L. and others. Moscow: Soviet encyclopedia. 1990. Vol.2 (Daf-Med). 671p. (russian) 
[8] V.P. Vasiliev. Analytical chemistry. Part 1. Gravimetric and titrimetric methods of analysis. Moscow: High School. 1989. 320p. (russian)

[9] Yu.N. Sakharov et al. Mechanism and kinetics of decomposition of phosphate raw materials. Bulletin of Kazan Technological University. 2011. No.11. (russian)

[10] Yu.N. Sakharov, I.A. Makhotkin, A.F. Makhotkin. Generalization of the regularities of the kinetics of the processes of decomposition of phosphate and apatite with solutions of phosphoric and sulfuric acids. Bulletin of Kazan Technological University. 2015. Vol.18. No.22. (russian) 